\title{
Smart Traffic Sign Games: Interactive Learning Multimedia Based on Interactive Surface and Augmented Reality for Elementary School Students
}

\author{
Anton Agus Setiawan \\ Faculty of Education \\ State University of Malang, Indonesia \\ antonsetiawan3@gmail.com
}

\author{
Ahmad Nur Yasin \\ Faculty of Education \\ State University of Malang, Indonesia \\ yasin.ahmadn@gmail.com
}

\author{
Andisa Talenta Oktaviani \\ Faculty of Engineering \\ State University of Malang, Indonesia \\ andisaviany@gmail.com
}

\begin{abstract}
Smart Traffic Sign Games utilizes interactive surface technology, Smart Traffic Sign Games offers a uniqueness that is with interactivity and ease of play. Through Smart Traffic Sign Games, a desktop/computer app based game, now we no longer need a large space, easy application dissemination process, otherwise cheaper than having to build real traffic parks on outdoors. The concept of developing a traffic park on interactive surface transforms the classroom surface into an interactive/touch screen by creating a virtual traffic environment projected through the projector to the floor surface, through the help of the Wii Remote and infrared sensors mounted on toy cars. When the toy car is driven in accordance with the design games, it will appear some commands, warning, or prohibition know the traffic signs. When the toy car is run by the student and approaches one of the traffic signs, an audio will appear that explains the function and purpose of the traffic signs. If a toy car violates the rules of traffic signs, there will be audio explaining the warnings and restrictions. Smart Traffic Sign Games is also equipped with augmented reality technology that lies in the Guide Book to add interactivity and attractiveness by synergizing the real world with the digital world. It is expected that this application can support traffic learning in the 2013 curriculum.
\end{abstract}

Keywords: interactive surface, barcode scanning, instructional media, fine motor skill, islamic education

\section{INTRODUCTION}

The number of traffic accidents occurring in Indonesia is still very high. Although the number of accidents in 2018 is lower than 2017 but Indonesia is still in the rank of 2 countries in ASEAN with high traffic accident numbers as submitted by Kakorlantas Polri Irjen Pol. Royke Lumowa at the 2017 ASEAN Police Forum held in Bali and Jakarta.

The high number of traffic accidents indicates that the ethics and culture of Indonesian people's traffic are still low. One of the efforts to form ethics and culture of orderly traffic is by the inclusion of traffic learning on the subject of Citizenship Education in Curriculum 2013.

Education and teaching problems are quite complex issues because of many factors that influence them. One of the factors is teacher. Teachers are an important and essential component to the success of the teaching and learning process. Teacher's job is to deliver learning materials to learners through communication interaction in teaching and learning process that is done.

The success of teachers in conveying the material depends on the smooth communication interaction between teachers and learners. In learning, teachers as the spearhead of education are required to create an effective and enjoyable learning environment.

Teachers should give more attention to the teaching components such as teaching objectives, instructional media, teaching strategies, teaching methodologies, teaching facilities and infrastructure as well as evaluation of teaching. Multimedia learning itself is a very important tool, to facilitate and support teachers in solving learning problems. With various methods, can improve the quality of learning to be higher. However, the awareness of teachers and educational institutions today in using multimedia learning is still considered less.

Urgency for interactive multimedia learning traffic increasingly high considering the start of implementation of traffic learning in the Curriculum 2013. Early traffic education should be prioritized by doing the maximum education through learning in formal schools. Smart Traffic Sign Games is expected to be a creative innovation that becomes a solution.

The goals to be achieved are: (1) explain the concept of utilization of Smart Traffic Sign Games as an effort to instill the culture of orderly traffic since early; (2) explain how the working mechanism of Smart Traffic Sign Games; and (3) xplain what are the benefits or impacts of the implementation Smart Traffic Sign Games?

\section{METHODS}

The method used in this design has six stages. The stage starts from determining the concept, design, material collection, design, and testing.

\section{Concept}

At the concept stage, the thing to do is analyze the audience, analyze the needs. Audience analysis aims to determine the level of security of the interactive surface to be designed. 


\section{Design}

At this stage determine the working system of the interactive surface is based on the study of literacy and needs analysis has been done.

\section{Collection of Tools and Materials}

In this case is the stage of collecting materials as needed in interactive surface design. Required materials consist of hardware and software, both used in the design process and tools / materials used as support in the interactive interactive utilization.

\section{Development}

Development is a step that can be done after the design step and the collection of tools \& materials is completed. In this development stage the results of the design phase used as a reference, by utilizing the tools and materials used in this interactive surface development.

The first development that can be done is to modify the device (pen, car, etc.) by adding infrared LED which will be used as a tool to interact on the surface. Then it can be continued with the design of the devices that will be used just like the position WiiMote, projector, surface and some other devices that support it.

\section{Testing}

This stage is done after the entire design process is completed. In this test phase has a function to test the smoothness of interactive surface that has been designed. Testing includes the accuracy or precision of existing sensors as well as testing of devices that have been modified by the addition of infrared LEDs. So the results of this test ensure that the developed interactive surface is feasible for further exploitation.

\section{RESULTS}

\section{Hardware \& Software Analysis}

In designing interactive surface, supporting facilities such as hardware (hardware) and software (software) is very supportive in the implementation of design. Here are the hardware and software used in the design of an interactive surface. The hardware used are: LCD projector; Laptop / Computer; WiiMote; Bluetooth; and Infrared LED. LCD projector is a hardware that serves to project the appearance of computer / laptop to the surface that will be made interaction with a larger display size and can be tailored to the needs of users.

WiiMote is a hardware device from Nitendo which is usually used as a device in playing games. WiiMote is a wireless communication device that transmits and receives data through bluetooth media.Wii has a bluetooth feature with a driver of type Broadcom 2042. This chip is a bluetooth class 2 that supports full bluetooth HID (Human Interface Device) with 8051 microprocessor 16 bit and WiiMote onboard memory does not require authentication or encryption in connection with other devices.

The WiiMote (Figure 1) that is utilized for this project is an infrared camera located on the remote front end. This camera has a resolution of $1024 \times 768$ with installed hardware to track infrared up to 4 dots at $100 \mathrm{~Hz}$. This camera contains a Charge Couple Device (CCD) with an additional infrared filter that can recognize light within the near infrared spectrum, at wavelengths greater than $800 \mathrm{~nm}$.

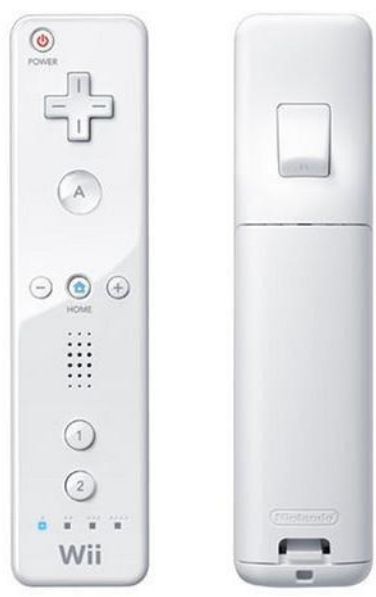

Figure 1

WiiMote

Bluetooth (Figure 2) is a wireless communication technology that operates in the 2.4 $\mathrm{GHz}$ frequency band. These devices provide data communications services in real time with a distance of approximately $10 \mathrm{~m}$. In designing this interactive surface bluetooth serves as a connection between WiiMote with a computer / laptop.

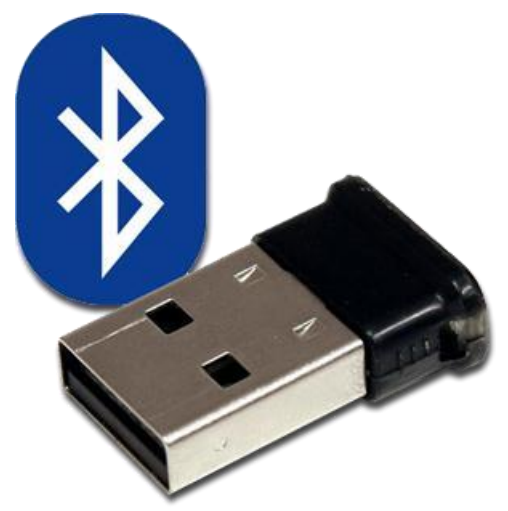

Figure 2

Bluetooth Dongle

Infrared is the energy of radiation with frequencies below the sensitivity of the human eye, so the human eye can not see with the naked eye of the infrared LED. To find out or see the incandescent infrared LED can take advantage of existing cameras on the smartphone. In designing this interactive surface the recommended infrared LED selection is type Vishay TSAL 6400 (Figure 3). 


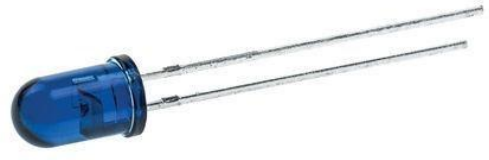

Figure 3

Infrared LED Type Vishay TSAL 6400

The software used in this design is: SmootBoard, Delphi 7, Adobe Photoshop, and Adobe Audition. Of the four software is divided into two different functions. The first function is useful in interactive interface design is SmootBoard software. The software plays a role in the implementation of calibration (sync display computer / laptop with the projection on the surface).

The second function is the software used in developing applications for fine motor learning. Delphi 7 is a software used to develop a program. Adobe Photoshop is used in designing interfaces that will be incorporated into Delphi 7 for programming. While Adobe audition is used for audio editing, which later audio is used as background music or sound effects on applications used for soft motor learning.

Working system of interactive surface is started from computer / laptop connection with projector. The projector projects the appearance on the surface according to the required size. Then bluetooth dongle installed on the computer / laptop, which then bluetooth is used to connect WiiMote with computer / laptop.

After multiple devices are connected, incandescent infrared LEDs are driven on the projection on the surface read by camera sensors. In the arrangement of devices used on interactive surface there are several alternative arrangements, it is tailored to the needs of users. Here is a description of the component attenuation used on the interactive surface (Figure 4). Infrared on WiiMote can serve as a mouse replacement like on a laptop.

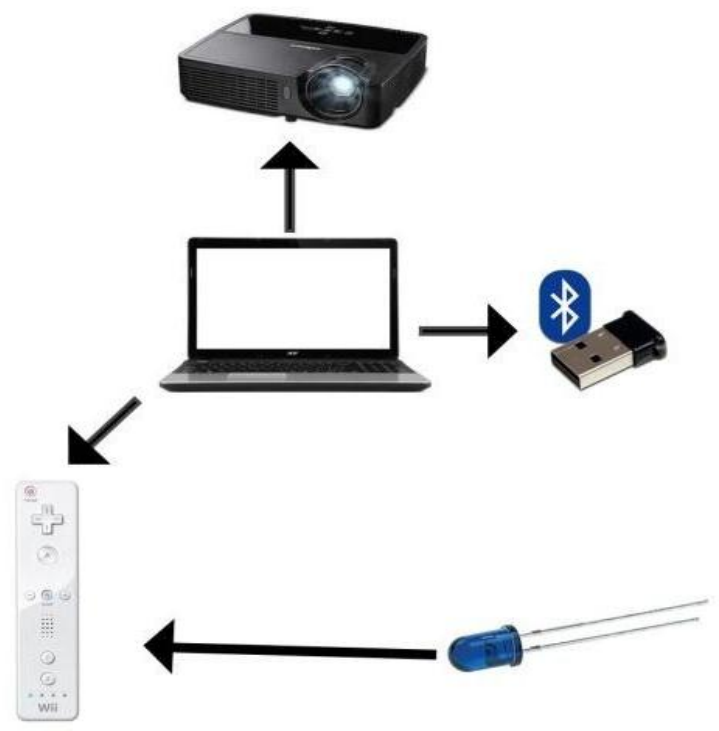

Figure 4

Interactive Surface System

\section{Surface Design Setup}

Here is a description of the component attenuation used on the interactive surface (Figure 5, 6, \& 7). From the Table 1, above can be concluded that, the further distance WiiMote with the surface then the wider the projection size that can be used. Vice versa, if the closer the WiiMote to the surface the narrower the projection size can be utilized.

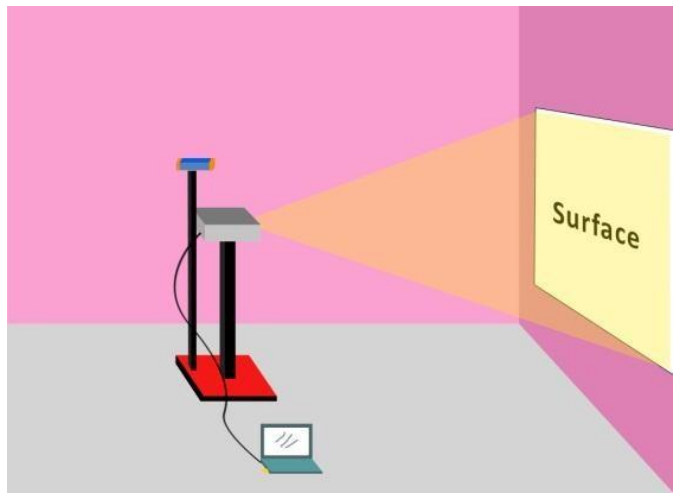

Figure 5

Surface Vertical Position

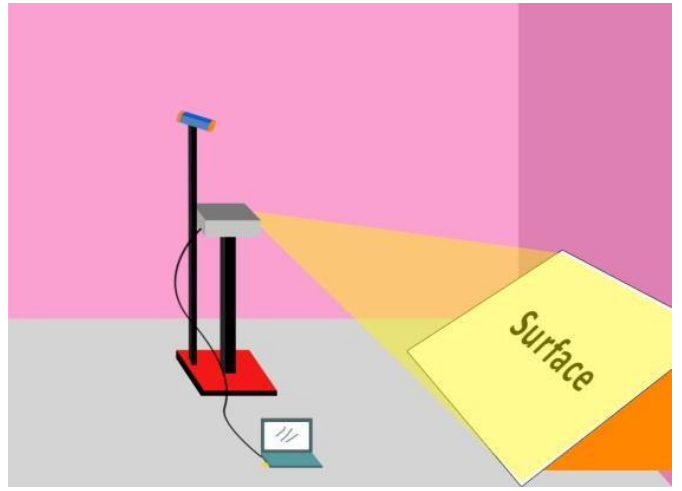

Figure 6

Position Surface Diagonal

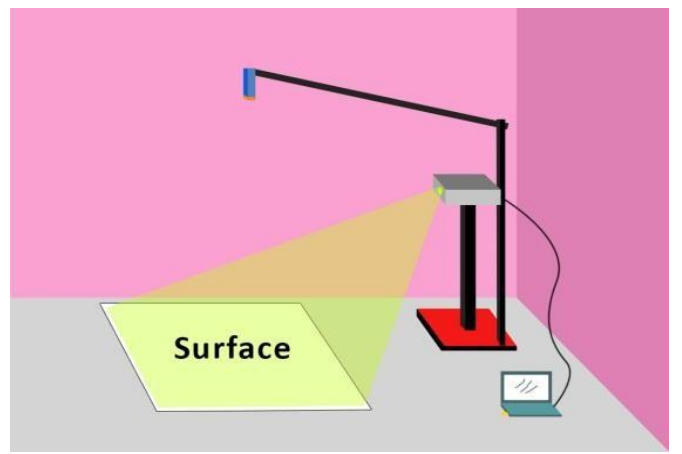

Figure 7

Surface horizontal position

Table 1

Comparison of WiiMote Distance with Projection Size

\begin{tabular}{|l|l|}
\hline \multicolumn{1}{|c|}{ WiiMote Distance } & Projection Size \\
\hline 2 meter & $80 \mathrm{~cm} \times 60 \mathrm{~cm}$ \\
\hline 3 meter & $109 \mathrm{~cm} \times 82 \mathrm{~cm}$ \\
\hline 4 meter & $137 \mathrm{~cm} \times 100 \mathrm{~cm}$ \\
\hline
\end{tabular}




\section{Interactive Surface}

\section{DISCUSSION}

Interactive surface can be interpreted as an interactive surface / touch screen where users can interact with whatever surface is then responded by the system. Evans and Rick (2014) argue that the "natural interface" provides an unique opportunity for designers to support collocated collaborative and kinesthetic learning experiences. Thus the interactive surface provides an opportunity for the learners to interact naturally with the subject matter presented.

Interactive surface is actually a technology combines LCD projectors and computers with touchable boards for control and application programs running on the operating system (windows). With the modification being interactive surface so that its utilization should not always be projected vertically / on the board, but also can be projected on any surface as it is projected horizontally or diagonally depending on user needs.

In the interactive interface design requires infrared LED devices and WiiMote as the main device. Surface that will be used to interact has been projected as a display on a laptop / computer. Users interact on the surface using infrared LEDs captured by infrared cameras on WiiMote. The advantage of interactive surface use by Swan (2010) is that interaction with digital content involving the manipulation of information with fingers and pens, makes learning with interactive surface more active, kinesthetic, and attractive. In his research Thomas notes all the advantages to student motivation and behavior, pedagogic thinking is also deeper with teachers who use technology every day than ever before (Miller, 2010).

\section{Soft Motor}

The development of motor in children is divided into two, namely hard motor and soft motor. Hard motor require coordination of certain muscle groups of children that can make them jump, climb, run, ride bicycles. While soft motor require hand and eye coordination such as drawing, writing, running toy car. Soft motor is a subtle movement involving certain parts of a small muscle, because it does not require power (Susanto, 2011). Yet this delicate movement requires careful coordination. The limitations of the interactive surface were built up design are perfect fit for school that has no means and radiant for delicate soft motor lessons (Purwodani \& Soepriyanto, 2017).

\section{Interavtive Learning Multimedia}

Learning with interactive multimedia according to Darmawan (2012) able to active students to learn with high motivation because of its interest in multimedia systems capable of presenting text, image, video, sound, and animation. Learning multimedia is used as a means of communication and interaction between teachers and learners (Arsyad, 2011). Students can be eager to learn with interactive multimedia because it looks interesting and supports learning. The combination of text, images, video, sound, and animation can be a learning resource for students. Interactive multimedia is a multimedia display that is designed to display the function to inform the message and have interactivity to users. Based on these definitions, interactive learning multimedia serves to facilitate learners learn the subject matter presented by the teacher and overcome the limitations of space, time, energy and senses (Daryanto, 2010).

The cone of Edgar Dale's experience illustrates that the learning experiences learned by learners can be through the process of deed or experience what they learn, the process of observing, and listening through certain media and the process of listening through language. The cone of experience (the experience composed of the most abstract and to the least abstract at the bottom). The cone of experience presented by Edgar Dale provides an illustration that the learning experience that learners can get through the process of deed or experience themselves what is learned, the process of observing and listening through a certain multimedia and the process of listening through the language.

Principles of the use of multimedia learning to be truly useful in learning among others: (1) multimedia that will be used teachers should be appropriate and directed to achieve the learning objectives; (2) multimedia to be used must be in accordance with learning materials (3); multimedia learning must be in accordance with interests, needs, and conditions of students; (4) multimedia to be used must pay attention to the effectiveness and efficiency; and (5) multimedia used must be in accordance with the ability of teachers in operating it (Sanjaya, 2007).

\section{Cooperative Learning}

According to Slavin, cooperative learning methods, students work together in four members teams to master material initially presented by the teacher (Isjoni, 2011). This means that cooperative learning is a learning model where learning and work systems with small groups collaboratively so as to stimulate learners to be more passionate about learning. The objectives of cooperative learning include at least three learning objectives, namely academic learning outcomes, acceptance of diversity, and the development of social skills.

Some of the advantages include: teaching learners to believe in the teacher, the ability to think, finding information from other sources and learning from other learners, encouraging learners to express their ideas verbally and comparing with the ideas of their friends, and helping learners to learn to respect the participants smart learners and weak learners, also accept this distinction.

\section{Augmented Reality}

Azuma (2017) defines Augmented Reality as the incorporation of real and virtual objects in real environments, runs interactively in real time, and there is integration between the three dimensions, the virtual object integrated into the real world. According to Borko (2011), Augmented Reality is a direct or 
indirect view of physical objects by adding information and can be displayed virtually. Virtual objects serve to display information that is unacceptable to humans. This makes reality more useful as a tool to help the user's perception and interaction with the real world. Information displayed by virtual objects helps users carry out activities in the real world.

\section{CONCLUSION}

Interactive surface is an utilization of the latest technology by using game device in its design. In interactive interactive development there are several layouts that can be utilized in accordance with the needs of users. The smooth operation of the interactive surface depends on adjusting the width of the projection by the distance with WiiMote.

Utilizing interactive surface in the learning activities can make the learning process more interesting, fun and centered on the learners. Interactive surface is one of interesting and fun media that facilitate communication interaction between teacher to learners. It is expected that Smart Traffic Sign Games Based on Interactive Surface and Augmented Reality can be a smart solution for traffic learning in the implementation of the 2013 curriculum.

\section{REFERENCES}

[1] Arsyad, A. 2011. Media Pembelajaran. Jakarta: Raja Grafindo Persada.

[2] Azuma, R. T. 2017. Making Augmented Reality a Reality. Proceedings of OSA Imaging and Applied Optics Congress, San Fransisco.

[3] Borko, C. F. 2011. Augmented Reality: An Overview. In Fuhrt, B., (Ed.), Handbook of Augmented Reality. Florida: Springer.

[4] Darmawan, D. 2012. Inovasi Pendidikan. Bandung: PT Remaja Rosdakarya.

[5] Daryanto. 2010. Media Pembelajaran: Peranannya Sangat Penting dalam Mencapai Tujuan Pembelajaran. Yogyakarta: Gava Media.

[6] Evan, M., \& Rick, J. 2014. Handbook of Research on Educational Communications and Technology. New York: Springer.

[7] Isjoni. 2011. Cooperative Learning: Efektivitas Pembelajaran Kelompok. Bandung: Alfabeta.

[8] Miller, D. 2010. Interactive Whiteboards: A Literature Survey. Interactive Whiteboard for Education, 2(1), 1-14.

[9] Purwodani, D. L., and Soepriyanto, Y. 2017. Rancang Bangun Interactive Surfaace untuk Pembelajaran Motorik Halus. Semnasinotek, 1(1), 137-142.

[10] Sanjaya, W. 2007. Strategi Pembelajaran Berorientasi Proses. Jakarta: Kencana Prenada Media Grup.

[11] Susanto, A. 2011. Perkembangan Anak Usia Dini. Jakarta: Kencana Prenada Media.

[12] Swan, K. 2010. Interactive Whiteboards and Student Achievement. Interactive Whiteboard for Education, 2(9), 131-138. 